Revistade
Economida
Contemporâned

\title{
MENSURAÇÃO DA DESIGUALDADE EDUCACIONAL ENTRE OS MUNICÍPIOS NORDESTINOS
}

\author{
Luciana de Oliveira Rodrigues ${ }^{a}$ \\ Jair Andrade Araujo ${ }^{b}$ \\ João Paulo Martins Guedes ${ }^{c}$ \\ Maria Micheliana da Costa Silva ${ }^{d}$
}

\begin{abstract}
aAnalista de Políticas Públicas do Instituto de Pesquisa e Estratégia Econômica do Estado do Ceará (IPECE). 'Professor do Curso de Pós-Graduação em Economia Rural da UFC.

'Professor Adjunto do Departamento de Economia da Universidade Federal do Rio Grande do Norte (UFRN). dProfessora adjunta do Departamento de Economia Rural da Universidade Federal de Viçosa.
\end{abstract}

Artigo recebido em 13/05/2016 e aceito para publicação em 03/05/2017.

RESUMO: O objetivo deste artigo é analisar a desigualdade educacional da Região Nordeste com base nos dados do Censo Demográfico de 2010. Para este fim, foi calculado o Índice de Gini Educacional (IGE) para a parcela da população economicamente ativa com 15 anos ou mais de idade, residentes nos 1793 municípios nordestinos. Foram empregadas as técnicas de Análise Exploratória de Dados Espaciais (AEDE) e Análise de Regressão Espacial para detectar a importância de algumas variáveis relacionadas ao contexto das famílias, do sistema educacional e da economia dos municípios sobre o Îndice de Gini Educacional. Verificou-se que o estado da Bahia apresentou a menor desigualdade educacional no Nordeste, com IGE de 0,394, enquanto o maior índice de desigualdade foi detectado no estado de Alagoas $(0,467)$. Quanto à analise espacial, foi detectada dependência espacial no tocante à desigualdade educacional entre os municípios e seus vizinhos. Constatou-se também que a renda per ca-

Correspondência para: Luciana de Oliveira Rodrigues

Contato: lrodrigues_s@hotmail.com 
pita, a frequência escolar líquida, a presença de IES e o PIB per capita municipal contribuem na redução da desigualdade, e que o baixo impacto de variáveis relacionadas ao sistema educacional pode ser atribuído ao seu efeito no longo prazo e, portanto, ressalta-se a importância do investimento e as políticas públicas educacionais, que só terão reflexo na redução da desigualdade educacional dos municípios no futuro.

PALAVRAS-CHAVE: Nordeste; desigualdade educacional; Índice de Gini Educacional (IGE); dependência espacial.

CLASSIFICAÇÃO JEL: C21; I25; J24. 


\title{
MEASURING EDUCATIONAL INEQUALITY AMONG NORTHEASTERN'S COUNTIES
}

\begin{abstract}
This study aims to analyze educational inequality in the Northeast Region of Brazil based on data from the 2010 Census. For this purpose, the Educational Gini Index (IGE) has been estimated for the portion of the economically active population aged 15 years and over residing in the 1793 municipalities of the Northeast. Analytical techniques included Spatial Data (ESDA) and Spatial Regression Analysis to detect the importance of a number of variables related to household, education and the economy of counties accounted for in the IGE. Results suggest that the state of Bahia shows the lowest educational inequality rates among all Northeast states, while Alagoas is the one with the highest inequality rate (0.467). As for the spatial analysis of educational inequality, spatial dependence has been detected regarding the municipalities and their neighbors. It has also been found that per capita income, net school attendance, IES presence and municipal per capita PIB contribute to the reduction of inequality. And the low impact of educational variables can be attributed to their long-term effect; as a result, investment and public policies directed to educational become really important, since they will only have an impact on the reduction of educational inequality among the municipalities in the long run.
\end{abstract}

KEYWORDS: Northeast; educational inequality; Educational Gini Index (IGE); space dependence. 


\section{INTRODUÇÃO}

A igualdade de acesso à educação é um dos direitos humanos básicos e que deve beneficiar a todos. Neste sentido, a redução da pobreza e o acesso da população menos favorecida a serviços básicos, como educação gratuita, estão diretamente relacionados à melhoria da qualidade de vida das pessoas em diferentes contextos sociais e econômicos. Portanto, se a educação é essencial para fomentar o crescimento econômico e reduzir a desigualdade e a pobreza, a velocidade e a continuidade pelo qual o processo educacional se expande estão diretamente relacionadas à sustentabilidade e ao desenvolvimento econômico de uma região (BARROS, HENRIQUES e MENDONÇA, 2002).

No Brasil, a partir da década de 1990, observaram-se avanços expressivos na expansão educacional em todos os estados. Neste período, o ensino fundamental foi praticamente universalizado e houve uma significativa expansão no ensino médio, sendo que metade da geração nascida na década de 1980 chegou a ingressar neste nível de ensino (MENEZES-FILHO, 2008). Essa conquista se deve à aprovação da Constituição Federal de 1988, que expõe de forma explícita o dever do Estado de ofertar gratuitamente a educação elementar, sendo responsabilidade dos estados e municípios a oferta do ensino fundamental e médio a todas as crianças e adolescentes em idade escolar.

No entanto, apesar do aumento da escolaridade da população, a desigualdade educacional, no Brasil, ainda apresenta lacunas surpreendentes entre os estados e as regiões, como têm mostrado vários estudos. (BAGOLIN e PORTO JR., 2003; SULIANO e SIQUEIRA, 2012; VIEIRA, ALBERT e BAGOLIN, 2008). Em Netto Jr. e Figueiredo (2009), por exemplo, constata-se que o Nordeste brasileiro é a região que apresenta o maior índice de desigualdade educacional, e a única com desigualdade superior à média do Brasil no período de 1986 a 2005.Viana, Salvato e França (2011) encontraram evidências da redução da desigualdade de renda e educacional entre as regiões brasileiras nos anos de 2003 e 2009. No entanto, segundo os autores, o Nordeste ainda apresenta as maiores desigualdades.

Contudo, grande parte dos estudos de desigualdade educacional no Brasil é de amplitude macro, ou seja, são analisadas as desigualdades entre os estados e as Grandes Regiões. Em nenhum deles a desigualdade educacional é explorada dentro de cada estado, por município e, portanto, não se levam em consideração as suas heterogeneidades. Dessa forma, torna-se necessário entender a desigualdade educacional e as transformações ocorridas dentro dos estados nordestinos nos últimos anos, levando-se em consideração os avanços nos níveis de instrução de sua população e as disparidades educacionais entre municípios mais desenvolvidos e municípios mais pobres. 
Portanto, este artigo tem por objetivo analisar a heterogeneidade educacional entre os municípios localizados na Região Nordeste. Para tanto, será utilizada a metodologia da construção do Índice de Gini Educacional (IGE), um dos principais métodos usados na literatura para medir desigualdade.

A proposta é entender o quanto a escolaridade influencia as desigualdades educacionais entre os municípios. Além disso, procura-se verificar se existe redução da desigualdade educacional, dada a presença ou não de polos de IES nos municípios, e qual é seu efeito sobre sua vizinhança. Para essa análise, fez-se uso da metodologia de Análise Exploratória de Dados Espaciais (AEDE) e Análise de Regressão Espacial, para detectar a importância dessas instituições de ensino superior na redução da desigualdade educacional.

Além dessa introdução, o trabalho é composto por mais quatro seções. A segunda seção dedica-se ao levantamento da literatura sobre o tema. Na terceira, apresentam-se a base de dados e a metodologia empregada neste estudo, tanto a metodologia da construção do IGE quanto a da análise espacial. Na quarta seção são analisados os resultados do IGE e das regressões aplicadas. Por fim, são apresentadas as principais conclusões do estudo.

\section{REVISÃO DA LITERATURA}

\subsection{A IMPORTÂNCIA DA EDUCAÇÃO PARA O CRESCIMENTO E DESENVOLVIMENTO ECONÔMICO}

Existe uma ampla discussão acadêmica sobre a importância da educação no aumento do bem-estar social e econômico de uma sociedade. Grande parte desses estudos defende a importância dos investimentos em educação justificando que a escolarização é indispensável para o desenvolvimento econômico de uma sociedade, não apenas pelos retornos privados, maior capital humano dos indivíduos, mas também por uma variedade de outras externalidades.

Segundo Becker (1962), os investimentos, por exemplo, em escolaridade, treinamentos nas empresas, assistência médica e até para o consumo de vitaminas trazem diferentes ganhos para os níveis de renda e consumo. Isso ocorre, segundo o autor, devido ao aumentando das habilidades físicas e mentais dos indivíduos, o que, por consequência, eleva as perspectivas de ganhos reais de renda no futuro. Já Schultz (1960), analisando as situações das nações subdesenvolvidas, afirma que o aumento do bem-estar dos pobres não dependia da terra, dos equipamentos ou da energia, mas sim do conhecimento. 
Mais recentemente, pesquisas realizadas por Barros, Henriques e Mendonça (2002), Soares, Fontoura e Pinheiro (2007) e Hanushek (2008) mostram que existe uma forte correlação entre o aumento da escolaridade e a redução da pobreza, melhor qualidade de vida social, redução das disparidades sociais e culturais, redução da criminalidade, dentre outros benefícios. E Hoffmann (2001) afirma que um aumento da escolaridade favorece a participação mais plena do cidadão na economia e na sociedade modernas.

Segundo Barro e Lee (2010), em uma perspectiva econômica, a educação desempenha um papel crucial na distribuição de renda e, consequentemente, no crescimento econômico. Quanto maior a proporção de pessoas em um país com alto nível de escolaridade, maior será a produtividade do trabalho. Ou seja, quanto mais distribuída for a educação entre a população, maior serão a capacidade e a competência de absorção de tecnologias detidas pela força de trabalho, o que torna possíveis a produtividade e o crescimento econômico.

A literatura também enfatiza que existem pelo menos três mecanismos pelos quais a educação afeta o crescimento econômico. Primeiro, ela pode aumentar o capital humano inerente à força de trabalho, aumentando a produtividade e, assim, afetando diretamente o nível de equilíbrio do produto no país. Em segundo lugar, esse efeito se dá pela capacidade de aumentar a tecnologia de inovação na economia pela habilidade de absorção de novos conhecimentos sobre novas tecnologias, produtos e processos. Em terceiro lugar, a educação pode facilitar a difusão e a transmissão do conhecimento necessário para entender e processar novas informações e incorporar novas tecnologias concebidas de outras economias, o que, por sua vez, promove o crescimento econômico (HANUSHEK e WOBMANN, 2010).

Além disso, Hanushek (2013) defende que o impacto do capital humano se torna ainda mais forte quando o foco se volta para o papel da qualidade da educação fornecida aos cidadãos. Para ele, as habilidades cognitivas adquiridas pela população - em vez de apenas o aumento da escolaridade - são importantes e positivamente relacionadas ao incremento e à distribuição da renda e, mais ainda, ao crescimento econômico de um país. Em uma análise sobre a importância da educação no crescimento econômico, Hanushek e Wobmann (2010) chegaram à conclusão de que, ao acrescentar a qualidade da educação em um modelo que incluía inicialmente apenas a renda inicial e anos de estudos para explicar o crescimento econômico, o ajustamento do modelo, dada a variação percentual das variáveis explicativas, passou de $25 \%$ para $73 \%$. Eles verificaram que a qualidade da educação mostrou ter peso maior e ser mais significativa sobre o crescimento econômico do que apenas a quantidade de anos de estudos. Neste sentido, países em desenvolvimento terão dificuldade em melhorar seu desempenho econômico em longo prazo se não investirem na melhoria da qualidade da educação ofertada (HANUSHEK, 2013). 
Contudo, mesmo em países em que a baixa qualidade da educação ainda é uma realidade, as políticas de expansão do ensino têm sido uma estratégia importantíssima para a ampliação da renda nacional, principalmente para os países em desenvolvimento. Ainda que a maioria das escolas nesses países não tenha educado seus alunos nos níveis mais elevados, evidências macro indicam que (em média) existe uma relação positiva entre cada ano adicional de estudo e o aumento das competências cognitivas dos indivíduos, refletindo diretamente no produto interno do país (BRETON, 2011).

Embora seja considerada um dos principais fatores de melhoria de renda e bemestar social, a educação também é apontada como um dos principais atributos da desigualdade salarial. Langoni (1974), em uma análise do retorno da educação sobre a renda dos trabalhadores das regiões Nordeste e Sudeste, foi um dos primeiros economistas no Brasil a mostrar a educação como um dos principais fatores explicativos da desigualdade, observando que o nível educacional pode contribuir com cerca de $58 \%$ da desigualdade de renda entre os indivíduos. Já Suliano e Siqueira (2012) encontraram evidências de que um ano a mais de estudos eleva a renda dos trabalhadores nordestinos em 16\%. Já no Sudeste, este retorno é um pouco menor, de cerca de $13 \%$, para cada ano adicional de estudo.

De acordo com Menezes-Filho (2001), pessoas com ensino fundamental completo ganham, em média, três vezes mais do que aquelas pessoas sem escolaridade. Além disso, o retorno de quem tem, pelo menos, um ano de faculdade é cerca de $150 \%$ maior do que aquele de pessoas que têm apenas o ensino médio completo. Isto significa um rendimento seis vezes maior que o daquelas pessoas sem escolaridade, e aqueles que completaram o ensino superior apresentam um ganho superior 12 vezes maior do que o daqueles sem nenhuma instrução escolar.

Nessa mesma direção, Sylwester (2002), ao analisar o efeito dos gastos em educação de 50 países sobre a redução da desigualdade, chegou à conclusão de que aqueles países que dedicam mais recursos para a educação pública, em porcentagem do PIB, têm menor desigualdade de renda nos anos seguintes, embora esse efeito seja lento. Outro resultado interessante encontrado pelo autor foi o de que em países mais desenvolvidos, como os países da OCDE, os efeitos dos gastos em educação sobre a redução da desigualdade são mais fortes do que em países menos desenvolvidos.

Em uma análise sobre a queda da desigualdade de renda no Brasil, Barros, Franco e Mendonça (2007) chegaram à conclusão de que um dos principais fatores da redução da desigualdade de remuneração do trabalho foi o aumento do capital humano via expansão educacional.

Portanto, para usufruir dos benefícios socioeconômicos e reduzir as disparidades educacionais e de renda entre os indivíduos, é necessário que grande parcela da população de um país esteja devidamente matriculada e com frequência escolar regular na idade certa. 
Também é necessário que essas pessoas recebam uma educação de qualidade, podendo, assim, ser absorvidas pela demanda de mão de obra e contribuir com o desenvolvimento da sociedade (MENEZES-FILHO, 2008), sendo que as políticas educacionais e o investimento em educação de boa qualidade estão diretamente relacionados à sustentabilidade e aos retornos de longo prazo da redução da pobreza em países de baixa renda.

\subsection{EXPANSÃO EDUCACIONAL E DESIGUALDADE REGIONAL}

No Brasil, o aumento da escolaridade se inicia, sobretudo, a partir da década de 1990, período marcado por expressivos aumentos no número de matrículas nas diferentes etapas de ensino. Segundo Menezes-Filho (2008), metade da geração nascida na década de 1980 ingressou no ensino médio. Uma das razões desta conquista foi a aprovação do art. 208 da Constituição Federal de 1988, que explicita ser dever do Estado a oferta obrigatória e gratuita do ensino fundamental, além de preconizar a extensão obrigatória e gratuita do ensino médio.

Nos últimos anos, o acesso ao estudo da população em idade escolar praticamente atingiu a universalização no país. Segundo dados do Censo Demográfico de 2010, aproximadamente $97 \%$ da população de 6 a 14 anos estavam frequentando a escola. Comparando-se ao ano de 2000, ocorreu um crescimento de mais de quatro pontos percentuais, quando, neste ano, apenas $92,5 \%$ das crianças na faixa de 6 a 14 anos estava frequentando escola ou creche.

Considerando ainda o Censo de 2010, mesmo com a quase universalização do ensino fundamental, o Brasil ainda tem aproximadamente 3,3\% das crianças e adolescentes nessa faixa de idade fora da escola, sendo que 1,3\% nunca a frequentou. Isso em termos absolutos representa mais de 371 mil crianças e adolescentes sem acesso ao sistema de ensino.

Os avanços relacionados a anos de estudos da população adulta (pessoas de 25 anos ou mais) também melhoraram o quadro na última década. Em 2010, 24,6\% dessa população tinham ensino médio completo e $11,3 \%$ tinham ensino superior completo.

Embora se perceba uma melhoria no acesso à educação e a quase universalização do ensino fundamental, ainda são observados grandes desafios no sistema educacional brasileiro, e um deles é a continuidade dos estudos da população jovem. Segundo dados do Censo de 2010, quase 50\% da população brasileira de 25 anos ou mais não tinha sequer completado o ensino fundamental. O problema se torna ainda maior quando são consideradas as desigualdades entre regiões. Sudeste e Sul são as mais homogêneas entre as regiões, isso porque, desde meados da década de 1980, elas vêm apresentando uma tendência à universalização de acesso ao ensino fundamental (CASTRO, 2000). 
Por outro lado, Norte e Nordeste apresentam as piores taxas de escolarização. Ainda segundo dados extraídos do Censo Demográfico de 2010, 59\% dos nordestinos com idade maior ou igual a 25 anos têm somente o ensino fundamental incompleto ou nenhuma instrução, e apenas 7,1\% tem o ensino superior completo, enquanto, no Sudeste, essa taxa é de aproximadamente $14 \%$.

Usando o Índice de Gini para medir a desigualdade educacional entre as regiões brasileiras, Netto Jr. e Figueiredo (2009) verificaram que o Nordeste brasileiro é a região que apresenta o maior índice de desigualdade educacional e a única com desigualdade superior à média do Brasil em todo o período analisado. Pelos resultados encontrados pelos autores, entre os anos de 1986 e 2005 o Gini do Capital Humano no Brasil caiu de 0,24 para 0,21 . Na região Nordeste houve uma redução de 0,28 para 0,24 e, embora tenha ocorrido uma redução mais acentuada do que a média brasileira, a desigualdade educacional entre a população nordestina ainda se encontrava significativamente superior à das demais regiões.

Usando a mesma metodologia, mas com dados mais recentes, Viana, Salvado e França (2011) encontraram evidências de que ocorreu redução da desigualdade educacional entre a população economicamente ativa em todas as regiões do Brasil entre o ano de 2003 e 2009. Dentro de uma classificação escalonada, o Sudeste foi a região com menor desigualdade educacional, mas o Nordeste ainda apresenta os maiores índices. Enquanto a redução na média nacional foi de 0,26 para 0,24 , no Nordeste, o Gini Educacional reduziu de 0,30 para 0,26. Considerando a desigualdade por Unidade Federativa (UF), o Piauí se destacou por apresentar o maior grau de desigualdade tanto de renda quanto em relação à escolaridade, o que foi medido pelos respectivos coeficientes de Gini.

Medeiro, Sales e Couto (2013) também mostraram evidências da desigualdade educacional com base na análise do Índice de Desenvolvimento Humano Municipal de Educação (IDHM) Educação ${ }^{1}$ entre os estados brasileiros. $\mathrm{O}$ índice foi calculado pelo Programa das Nações Unidas para o Desenvolvimento (PNUD) entre 2000 e 2010 de acordo com a classificação adotada pela PNUD, que classifica o IDHM-Educação

1 O IDHM-Educação, ou a medida de acesso ao conhecimento, é composto por indicadores de escolaridade da população adulta e do fluxo escolar da população jovem. A escolaridade da população adulta é medida pelo percentual da população de 18 anos ou mais de idade com ensino fundamental completo (tem peso 1), e o fluxo escolar da população jovem é medido pela média aritmética do percentual de crianças de 5 a 6 anos frequentando a escola, as de 11 a 13 anos frequentando os anos finais do ensino fundamental e o percentual de adolescentes de 15 a 17 anos com ensino fundamental completo e do percentual de jovens de 18 a 20 anos com ensino médio completo (com peso 2). Esse índice varia entre 0 e 1 , sendo que quanto mais próximo de zero, pior o desenvolvimento humano relacionado ao acesso ao conhecimento e quanto mais do limite superior, melhor. 
de um município inferior a 0,499 como sendo muito baixo e entre 0,500 a 0,599 como baixo. Foi observado que, no ano de 2000, grande parte dos estados brasileiros estava em situação muito ruim, sendo que a grande maioria tinha o IDHM-Educação dentro da categoria muito baixo. A análise dos dados mostra que houve uma melhora significativa no ano de 2010, mas a maioria dos estados do Norte e do Nordeste continua apresentando, na média, o IDHM-Educação baixo. No Nordeste, o Ceará foi o único Estado classificado na categoria médio, como mostra a Figura 1.

\section{Figura 1 - Mapas temáticos para o IDH-M, dimensão Educação, dos estados referentes aos anos de 2000 e 2010}
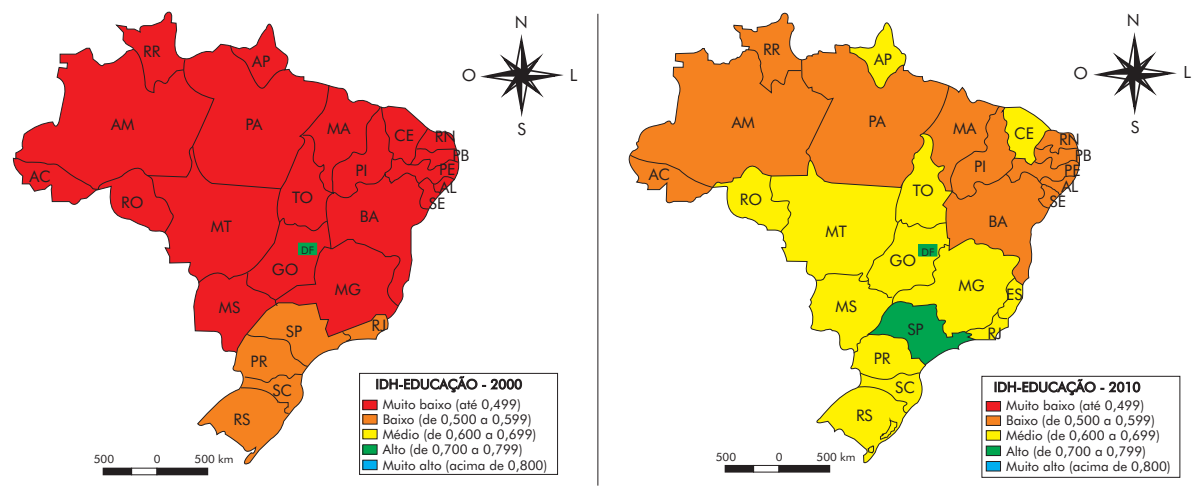

Fonte: Medeiro, Sales e Miro (2013).

A desigualdade educacional da população residente nos municípios dos estados nordestinos se torna mais evidente quando se analisa individualmente cada município. Visualmente, como pode ser observado na Figura 2, enquanto alguns municípios possuem índice de acesso ao conhecimento médio ou alto, seus vizinhos próximos estão entre os que possuem IDHM-Educação muito baixo. Além disso, apenas nove municípios alcançaram IDHM-Educação superior a 0,700 (alto).

Embora existam na literatura estudos que mostram empiricamente a desigualdade educacional na Região Nordeste, nenhum deles explora espacialmente a desigualdade em cada estado, por município. Essa abordagem sobre desigualdade educacional ainda é escassa na literatura. Portanto, a proposta deste estudo é analisar a desigualdade nos municípios nordestinos a partir da construção do Índice de Gini Educacional - IGE. 


\section{Figura 2 - Índice de Desenvolvimento Humano Municipal- IDHM-Educação para os municípios do Nordeste, 2010}

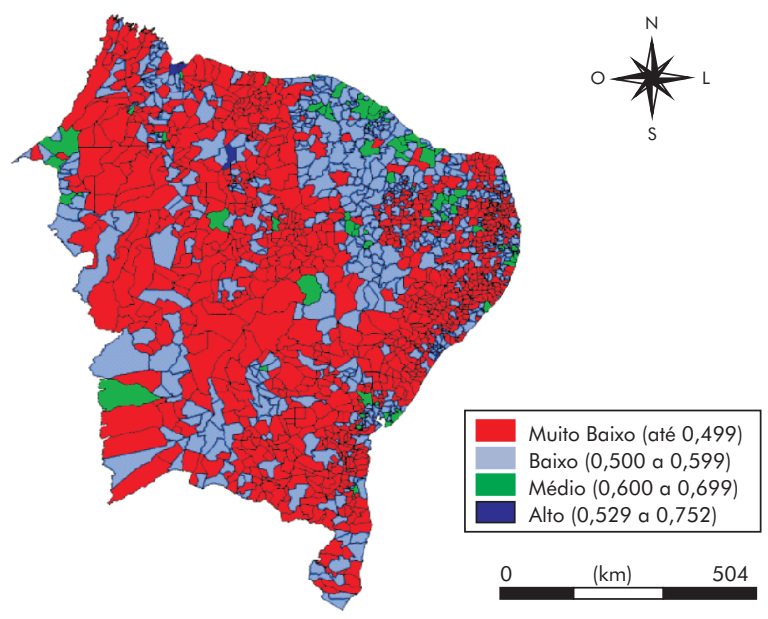

Fonte: Elaboração dos autores com dados da PNUD-IDHM-Educação.

\section{METODOLOGIA}

\subsection{CONSTRUÇÃO DO ÍNDICE DE GINI DE EDUCAÇÃO}

Para construir o Índice de Gini Educacional foram usados os dados do Censo Demográfico de 2010 do Instituto Brasileiro de Geografia e Estatística (IBGE). A metodologia é a mesma usada por Thomas, Wang e Fan (2000). Nos dados coletados pelo Censo Demográfico de 2010, tem-se nos anos de escolaridade uma variável discreta que assume o limite inferior (zero), indicando aquela parcela da população sem nenhuma escolaridade, sendo que um limite superior representa aquela população que tem ensino superior completo ou níveis superiores (mestrado e doutorado). Por esta razão, não seria possível o cálculo do Índice de Gini de fórmula direta ${ }^{2}$. Como alternativa, Thomas, Wang e Fan (2000) usam a seguinte equação adaptada para lidar com as especificações da variável escolaridade de uma população:

$$
\operatorname{Gini}_{g}^{E}=\left(\frac{1}{\mu}\right) \sum_{i=2}^{n} \sum_{j=1}^{i-1} p_{i}\left(y_{i}-y_{j}\right) p_{j}
$$

\footnotetext{
2 A fórmula direta do Índice de Gini é dada por: $G=\frac{1}{\mu N(N-1)} \sum_{i>j} \sum_{j}\left(y_{i}-y_{j}\right)$.
} 
Em (1), Gini $g_{g}^{E}$ é Índice de Gini Educacional para grandes populações; $\mu$ é a média de anos de escolaridade para a população de 15 anos ou mais em um determinado município. $\mathrm{O}$ cálculo é realizado por meio da seguinte expressão: $\mu=\sum_{i=1}^{n} p_{i} y_{i} ; p_{i}$ e $p_{j}$ representam a proporção da população com certo nível de escolaridade; $y_{i}$ e $y_{j}$, anos de escolaridade em diferentes ciclos de educação; e $n$ representa o número de níveis do ciclo educacional. Assim como no trabalho de Thomas, Wang e Fan (2000), $n=7$, onde cada categoria é dívida por:

1. Nenhuma escolaridade (ou analfabetos);

2. Ensino fundamental incompleto;

3. Ensino fundamental completo;

4. Ensino médio incompleto;

5. Ensino médio completo;

6. Ensino superior incompleto;

7. Ensino superior completo.

Expandindo a equação (1), obtém-se a forma detalhada do somatório do Índice de Gini Educacional:

$$
\begin{aligned}
\operatorname{Gini}_{g}^{E}=\left(\frac{1}{\mu}\right)[ & p_{2}\left(y_{2}-y_{1}\right) p_{1}+p_{3}\left(y_{3}-y_{1}\right) p_{1}+p_{3}\left(y_{3}-y_{2}\right) p_{2}+\cdots+p_{7}\left(y_{7}-y_{1}\right) p_{1} \\
& +p_{7}\left(y_{7}-y_{2}\right) p_{2}+p_{7}\left(y_{7}-y_{3}\right) p_{3}+p_{7}\left(y_{7}-y_{4}\right) p_{4}+p_{7}\left(y_{7}-y_{5}\right) p_{5} \\
& \left.+p_{7}\left(y_{7}-y_{6}\right) p_{6}\right]
\end{aligned}
$$

Em (2), $p_{1}$ é a proporção da população em um determinado município sem escolaridade; $p_{2}$ é a proporção da população com ensino fundamental incompleto; (...) $p_{7}$ é a proporção da população com ensino superior completo; $y_{1}$ é o ano de escolaridade para um indivíduo sem escolaridade; $y_{2}$ é o ano de escolaridade para um indivíduo com ensino fundamental incompleto. (...) $y_{7}$ é o ano de escolaridade para cada indivíduo com ensino superior completo.

Para calcular os anos de escolaridade para os sete níveis de ensino, foram utilizadas as seguintes somas:

Analfabetos: $y_{1}=0$

Ensino fundamental incompleto $y_{2}=y_{1}+0,5 C_{F}=0,5 C_{F}$

Ensino fundamental completo $y_{3}=y_{1}+C_{F}=C_{F}$

Ensino médio incompleto $y_{4}=y_{3}+0,5 C_{M}=C_{F}+0,5 C_{M}$

Ensino médio completo $y_{5}=y_{3}+C_{M}=C_{F}+C_{M}$

Ensino superior incompleto $y_{6} y_{5}+0,5 C_{S}=C_{F}+C_{M}+0,5 C_{S}$

Ensino superior completo $y_{7}=C_{F}+C_{M}+C_{S}$ 
Sendo:

$C_{F}$ anos de estudos necessários para completar o ciclo do ensino fundamental (8 anos);

$C_{m}$ anos de estudos necessários para completar o ensino médio (3 anos);

$C_{s}$ anos de estudos necessários para completar o ensino superior (4 anos).

Simplificando, é possível afirmar que um indivíduo que concluiu o ensino fundamental tem oito anos de estudos; aquele que concluiu o ensino médio, 11 anos de estudos; e o que obteve o título de ensino superior tem 15 anos de escolaridade. Os dados sobre os ciclos de cada nível de ensino são obtidos pela antiga legislação educacional, que considera o ensino fundamental de oito anos ${ }^{3}$. Assume-se ainda que as pessoas que receberam educação incompleta em cada ciclo de ensino conseguiram alcançar apenas metade do ciclo, como é mostrado nas equações (3.2), (3.4) e (3.6).

Como o valor do Índice de Gini mostrado na equação (1) é sensível ao tamanho da população, Thomas, Wang e Fan (2000) sugerem corrigir esse problema com o acréscimo do fator $\left[\frac{N}{N-1}\right]$. Portanto, para municípios com pequenas populações foi usada a equação:

$$
\operatorname{Gini}_{p}^{E}=\left[\frac{N}{N-1}\right] \cdot\left|\left(\frac{1}{\mu}\right) \sum_{i=2}^{n} \sum_{j=1}^{i-1} p_{i}\left(y_{i}-y_{j}\right) p_{j}\right|=\left[\frac{N}{N-1}\right] \cdot G i n i_{g}^{E}
$$

Em (4), Gini ${ }_{p}^{E}$ - representa o Índice de Gini para pequenas populações e $N$ é o número de indivíduos na população de 15 anos ou mais em determinado município de pequena população.

Os autores não especificam qual seria um tamanho de uma população para que ela seja considerada grande ou pequena. Portanto, para o banco de dados usado, será considerado um município pequeno aquele que tiver menos de cinco mil habitantes maiores que 15 anos de idade, o que representa aproximadamente $23 \%$ dos municípios nordestinos.

\subsection{ANÁLISE EXPLANATÓRIA DE DADOS ESPACIAIS E MODELAGEM ECONOMÉTRICA}

Antes de mensurar os fatores que contribuem para a desigualdade educacional entre a população nordestina, é necessário verificar se existe dependência espacial entre as variáveis analisadas. Neste estudo, aplicam-se técnicas de análise espacial, mais

3 Em 06/02/2006 é sancionada a Lei no 11.274 , com a qual passa a vigorar o ciclo do ensino fundamental com 9 anos. 
precisamente a elaboração de mapas temáticos; o uso de indicadores de dependência espacial global e local, finalizando com a modelagem econométrica para dados crosssection. Essas técnicas possibilitam estabelecer se as variáveis estudadas ocorrem de forma aleatória ou se existem evidências de algum tipo de dependência espacial, além de ser possível analisar alguns determinantes da sua distribuição (PÉREZ, 2005).

A Análise Exploratória de Dados Espaciais (AEDE) analisa indícios sobre a existência de padrões globais e/ou locais de associação espacial. Para desenvolvê-la devese, previamente, impor um arranjo que permita estimar coeficientes que mostrem o grau de interação entre as unidades espaciais (municípios, regiões etc.). Isso consiste em criar uma matriz de pesos espaciais $(W)$, cujo conceito é baseado na contiguidade, uma vez que regiões vizinhas possuem uma interação mais forte entre si do que regiões que não possuem fronteira em comum (ALMEIDA, 2004). Nessas situações, são utilizadas as matrizes definidas pelo princípio de contiguidade do tipo Queen (rainha) e do tipo rook (torres), sendo escolhida aquela que apresenta o maior valor do índice de I-Moran (YWATA e ALBUQUERQUE, 2011).

A fim de verificar a existência de autocorrelação espacial global do IGE, são realizados os testes de I de Moran e Local Indicators of Spatial Association (LISA). O I de Moran indica a existência de um padrão na distribuição espacial dos dados que varia de +1 a -1 , sendo que, quanto mais próximo do seu limite superior, mais forte será a concentração espacial, enquanto os dados estarão mais dispersos quando seu valor estiver mais próximo de -1 . E a estatística de LISA testa a existência de autocorrelação local, possibilitando a detecção da existência de clusters dados os valores de uma determinada variável no espaço (BRITO, SILVA e SILVA, 2013).

Como o Índice de Gini no $m$-ésimo município pode ser explicado por vários fatores, foram selecionados dentro de três conjuntos os que podem ter mais peso sobre ele. Dessa forma, pode-se estimar por Mínimos Quadrados Ordinários (MQO) a seguinte equação:

$$
\operatorname{Gini}^{E}=\beta_{0}+\beta_{1} \mathrm{Fam}_{m}+\beta_{2} E d u_{m}+\beta_{3} E c o_{m}+\varepsilon
$$

Em (5), Fam é um vetor de características das famílias no $m$-ésimo município; $E d u$ representa o vetor de variáveis referentes ao sistema educacional dos municípios; Eco é o vetor de variáveis que caracterizam a economia destes; e é o termo de erro, que se refere a fatores não observados.

Os efeitos de vizinhança sobre o Índice de Gini Educacional e as variáveis que o determinam são capturados ao se incorporarem defasagens espaciais sobre as variáveis dependente e independente, bem como sobre o termo de erro. Caso haja dependência espacial em quaisquer desses termos, a estimação por MQO gera estimativas ineficientes e/ou viesadas. 
Se a dependência espacial for constatada, é necessário escolher um modelo espacial mais adequado para a análise das variáveis. Portanto, são estimados três modelos com o objetivo de encontrar aquele mais ajustado para a análise proposta. O Modelo de Defasagem Espacial ou modelo SAR (Spatial autorregressive model) é mais adequado no caso em que há correlação espacial entre o IGE de um município e o de seus vizinhos próximos (ALMEIDA, 2012), o que é especificado pela seguinte equação:

$$
\operatorname{Gini}^{E}=\rho W \operatorname{Gini}^{E}+\beta X+\varepsilon
$$

Em (6), X é o vetor que contém as variáveis explicativas e $\rho$ é o coeficiente autorregressivo espacial. Os parâmetros são representados pelo vetor $\beta$. Caso o padrão espacial esteja no termo de erro, dado por efeitos não observados correlacionados espacialmente, devese aplicar o Modelo de Erro Espacial (Spatial Error Models - SEM), dado por:

$$
\operatorname{Gini}^{E}=\beta X+u+\varepsilon
$$

Em (7),

$$
u=\lambda W u+\varepsilon
$$

Nesse caso, o efeito espacial está refletido em $u$, que é o termo de erro da equação (8). E o vetor de resíduos $\varepsilon$ possui distribuição normal multivariada, com média zero e matriz de covariância $\sigma^{2} I$. O coeficiente escalar $\lambda$ é o parâmetro do erro autorregressivo espacial (YWATA e ALBUQUERQUE, 2011).

Por fim, o Modelo Kelejian-Prucha (SAC) abarca os dois modelos apresentados anteriormente, com a diferença de que ele considera tanto a defasagem espacial quanto o processo espacial que envolve o termo do erro (GOLGHER, 2015), então:

$$
\begin{gathered}
\operatorname{Gini}^{E}=\rho W \operatorname{Gini}^{E}+\beta X+u \\
u=\lambda W u+\varepsilon \\
\varepsilon \sim N\left(0, \sigma^{2} I_{n}\right)
\end{gathered}
$$

A estimação dos modelos é feita via Máxima Verossimilhança, e as decisões sobre qual é o melhor modelo a ser analisado serão feitas pelas análises das estatísticas do Critério de Informação de Akaike (AIC), que é expresso pela seguinte equação: $A I C=-2 \times L I K+2 k$, onde LIK é o log de verossimilhança maximizado, e $k$ é o número de coeficientes de regressão; e pelo critério de informação bayesiano (BIC). Segundo Lopes (2005), o modelo que apresentar o menor valor entre os critérios 
calculados é aquele que está melhor ajustado aos dados e, consequentemente, tem o maior LIK. Além disso, apresentam-se os testes (versão simples e robusta) do Multiplicador de Lagrange para identificar a presença da defasagem espacial ou dependência espacial do erro, ou a presença de ambas.

\subsection{BASES DE DADOS}

Depois de calcular o IGE da população economicamente ativa de 15 anos ou mais, explicado na seção 3.1, o próximo passo é verificar a relação da desigualdade educacional com outras variáveis no contexto municipal. A escolha desse grupo se deve ao fato de representarem a principal força ativa ou econômica da sociedade.

As variáveis escolhidas para a regressão no contexto familiar (backgroud) são as relacionadas à escolaridade do chefe de família que é calculada pelo percentual de chefes com ensino superior no município (chefe_es e chefe_es^2). A média da renda domiciliar per capita ( $\ln r d c p$ ) é calculada pela renda total de um determinado domicílio, dividida pelo número de membros na família - sendo as duas informações extraídas do Censo Demográfico de 2010. Para as características do sistema educacional do município foram usadas as taxas de abandono escolar do ensino fundamental ( $\left.t x \_a b \_e f\right)$ e médio ( $\left.t x \_a b \_e m\right)$ e as informações da presença de IES ${ }^{4}$, todas extraídas do Instituto Nacional de Estudos e Pesquisas Educacionais Anísio Teixeira, enquanto as taxas de frequência líquida do ensino fundamental e médio (tx_liquida ef e tx_liquida_em), bem como a taxa bruta (tx_bruta_ef e tx_bruta_em), foram coletadas do Ipeageo. Por fim, as variáveis que representam a economia de um determinado município foram selecionadas do PIB per capita municipal ( $\left.\ln \_p p c\right)$, e o Índice de Gini da renda (gini_renda), que mede o índice de desigualdade de renda de um determinado município, foi coletado do IBGE e do Censo Demográfico de 2010.

De acordo com os dados coletados, cerca de 3\% dos chefes de família da Região Nordeste já tinham concluído o ensino superior em 2010. A renda domiciliar per capita das famílias nordestinas estava em torno de 277 reais, em valores de 2010. A taxa média de abandono dos estudos dos municípios no ensino fundamental estava em torno de 6\%, e a no ensino médio, de 15\%. Em 17\% dos municípios existiam polos de IES. As desigualdades educacionais dos municípios estavam em torno, na média, de 0,525 escore, com limite inferior de 0,360 e superior de 0,790.

\footnotetext{
4 A presença de IES é uma dummy que assume valor "1" se no município existe a presença de polos de instituições de ensino superior - IES, e "0" no caso contrário.
} 
Tabela 1 - Estatísticas descritivas das variáveis explicativas, Região Nordeste, 2010

\begin{tabular}{|c|c|c|c|c|}
\hline Variáveis & Média & Desvio Padrão & Mín & Máx \\
\hline \multicolumn{5}{|l|}{ Famílias } \\
\hline Renda domiciliar per capita & 276,9 & 97,8 & 96,3 & 1144,3 \\
\hline Proporção de chefes de família com ensino superior & 2,8 & 1,8 & 0,0 & 19,0 \\
\hline $\begin{array}{l}\text { Proporção de chefes de família com ensino superior } \\
\text { - ao quadrado }\end{array}$ & 10,8 & 22,5 & 0,0 & 360,1 \\
\hline \multicolumn{5}{|l|}{ Sistema Educacional } \\
\hline Taxa de abandono no ensino fundamental & 5,7 & 3,3 & 0,0 & 34,1 \\
\hline Taxa de abandono no ensino médio & 14,7 & 7,0 & 0,0 & 55,8 \\
\hline Taxa bruta de frequência do ensino fundamental & 119,8 & 7,7 & 99,8 & 180,8 \\
\hline Taxa bruta de frequência do ensino médio & 63,2 & 14,2 & 14,1 & 126,2 \\
\hline Taxa líquida de frequência do ensino fundamental & 93,8 & 2,5 & 76,8 & 99,0 \\
\hline Taxa líquida de frequência do ensino médio & 32,4 & 8,7 & 7,1 & 81,3 \\
\hline Presença de IES & 0,17 & 0,38 & 0 & 1 \\
\hline \multicolumn{5}{|l|}{ Economia } \\
\hline Gini de renda & 0,525 & 0,049 & 0,360 & 0,790 \\
\hline PIB per capita Municipal & $6.032,74$ & $8.762,25$ & $2.404,20$ & $296.884,70$ \\
\hline
\end{tabular}

Fonte: Elaboração dos autores.

\section{RESULTADOS E DISCUSSÕES}

\section{1. ÍNDICE DE GINI EDUCACIONAL - IGE}

O Índice de Gini Educacional, assim como o Índice Gini de renda, varia de 0 a 1, onde 0 representa a completa igualdade entre os indivíduos e 1 a completa desigualdade. Sendo assim, quanto mais os valores do IGE se afastarem de 0 , maior será a desigualdade educacional entre a população de um determinado município.

A Tabela 2 apresenta a distribuição do IGE para cada Unidade da Federação (UF) da Região Nordeste, mostrando os municípios com menor e maior desigualdade. $\mathrm{Na}$ média, o estado com menor desigualdade educacional é a Bahia, com Gini de 0,381, seguido do Ceará $(0,404)$ e do Rio Grande do Norte $(0,404)$. Já os estados com maior desigualdade são Alagoas $(0,458)$ e Piauí $(0,443)$. 
Tabela 2 - Índice de Gini Educacional, Região Nordeste, 2010

\begin{tabular}{lcccc}
\hline \multicolumn{1}{c}{$\begin{array}{c}\text { Unidade da } \\
\text { Federação }\end{array}$} & Total de Municípios & Média & Min & Max \\
\hline Maranhão & 217 & 0,423 & 0,202 & 0,530 \\
Piauí & 223 & 0,451 & 0,270 & 0,591 \\
Ceará & 184 & 0,416 & 0,251 & 0,550 \\
Rio Grande do Norte & 167 & 0,415 & 0,245 & 0,517 \\
Paraíba & 223 & 0,449 & 0,257 & 0,548 \\
Pernambuco & 185 & 0,419 & 0,219 & 0,530 \\
Alagoas & 102 & 0,467 & 0,290 & 0,600 \\
Sergipe & 75 & 0,420 & 0,240 & 0,541 \\
Bahia & 417 & 0,394 & 0,207 & 0,586 \\
\hline Nordeste & 1.793 & 0,424 & 0,202 & 0,600 \\
\hline
\end{tabular}

Fonte: Elaboração dos autores com base nos resultados da pesquisa.

O município com menor desigualdade educacional está localizado no Maranhão, e é o município de Poço do Lumiar ${ }^{5}$, com IGE de apenas 0,202. O município com maior desigualdade educacional está localizado no estado de Alagoas (Traipu, com 0,600). A distribuição do IGE por município do Nordeste pode ser visualizada na Figura 3.

Para uma melhor analise são apresentados a seguir os mapas de cada estado nordestino de acordo com a distribuição do IGE para cada município. Na Figura 4, tem-se os estados do Maranhão e do Piauí. No Maranhão, os três municípios com menor desigualdade educacional são: Poço do Lumiar (0,0,205), já citado anteriormente, São Luiz $(0,211)$ e São José do Ribamar (0,231). Já aqueles com maior desigualdade são: Timbaras (0,528), São Francisco do Maranhão (0,529) e Fernando Falcão $(0,530)$. No Piauí destacam-se: Teresina (0,270), Floriano (0,306) e Parnaíba (0,331), estes com os menores IGE no estado. Destacam-se ainda Caxingó (0,578), Massapé do Piauí $(0,559)$ e Floresta do Piauí, por apresentarem os maiores índices de desigualdade entre os municípios piauienses.

5 O Município de Poço do Lumiar foi o terceiro município com melhor IDM-Educação do Nordeste em 2010, em resultado divulgado pela PNUD. 
Figura 3 - Índice de Gini Educacional (IGE), Nordeste, 2010

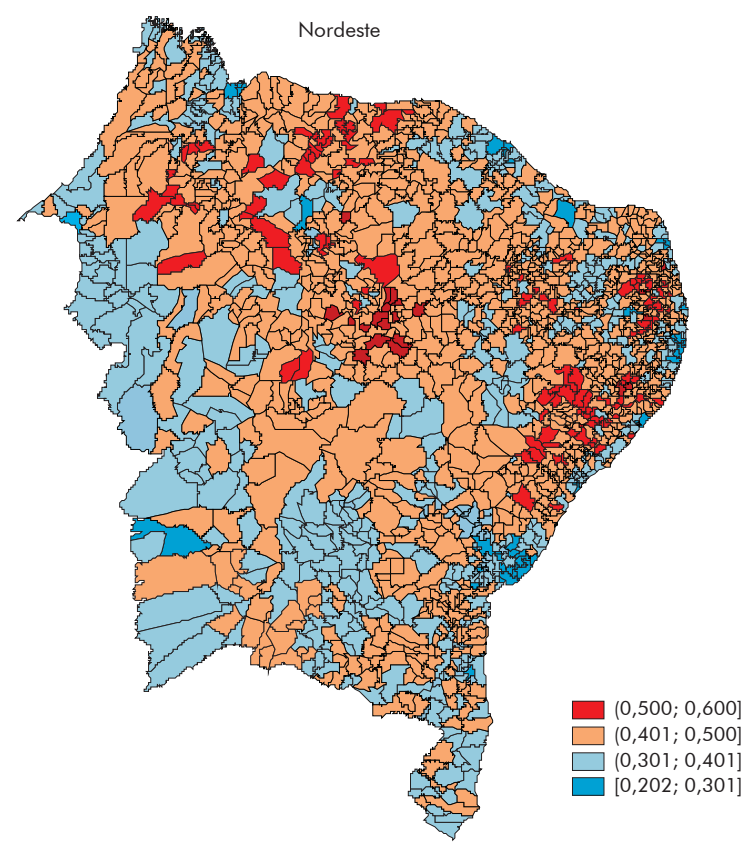

Fonte: Elaboração própria.

Figura 4 - Índice de Gini Educacional (IGE), Maranhão e Piauí, 2010
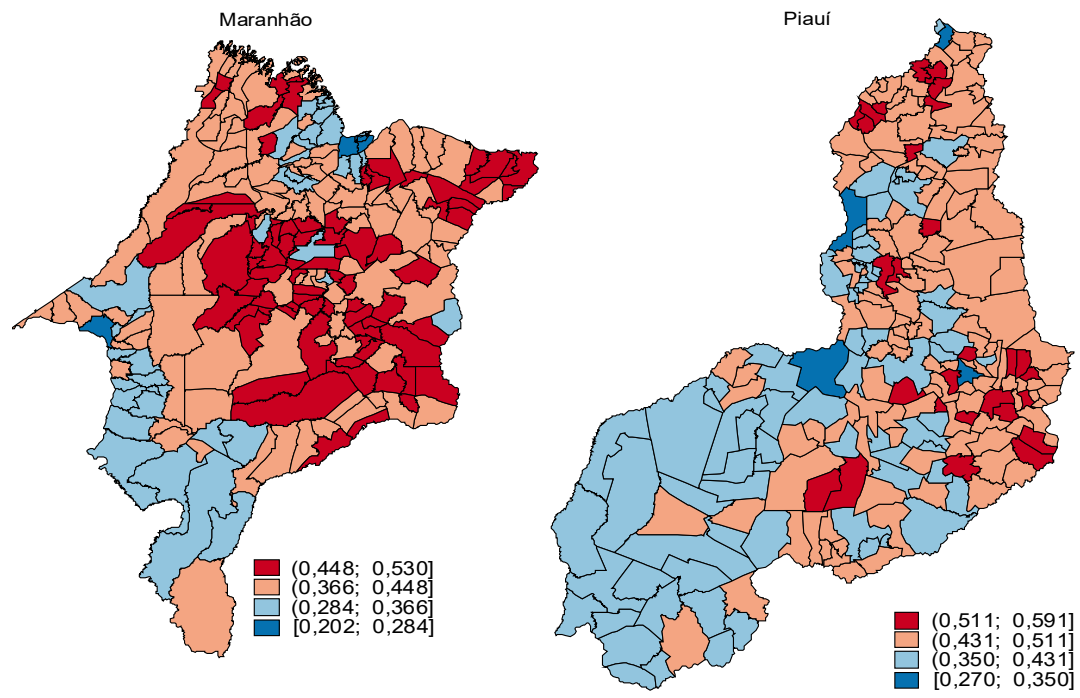

Fonte: Elaboração própria. 
Analisando o estado do Ceará, na Figura 5, nota-se que os três municípios que possuem as menores desigualdades educacionais estão localizados na região metropolitana. São eles: Fortaleza $(0,186)$, Maracanaú $(0,251)$ e Pacatuba $(0,257)$. Já Granja $(0,538)$, Barroquinha $(0,547)$ e Salitre $(0,550)$ foram os que apresentaram maior desigualdade educacional no estado. Quanto aos municípios do Rio Grande do Norte, também exposto na Figura 5, com menor desigualdade, destacam-se: Parnamirim $(0,245)$, Natal $(0,251)$ e São Gonçalo do Amarante $(0,294)$. Já aqueles que apresentaram as maiores desigualdades são: Espírito do Santo $(0,498)$, Venha Ver $(0,508)$ e Paraná $(0,517)$.

Figura 5 - Índice de Gini Educacional (IGE), Ceará e Rio Grande do Norte, 2010

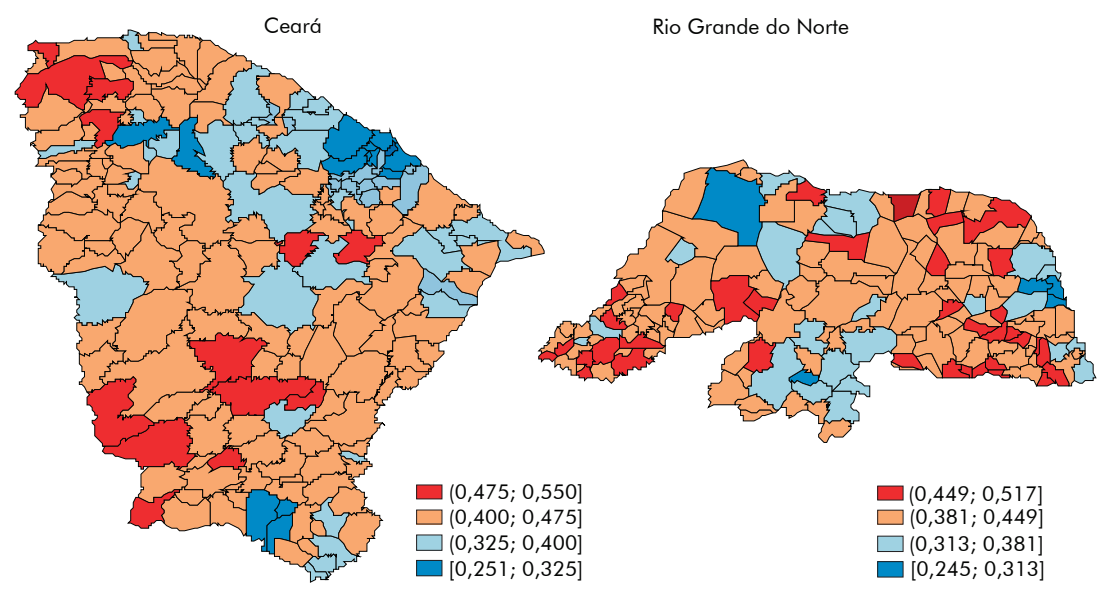

Fonte: Elaboração própria.

Em Sergipe, os municípios que atingiram os menores índices de desigualdade foram Aracaju (0,240), Nossa Senhora do Socorro (0,302) e São Cristóvão $(0,253)$. Por sua vez, os índices mais elevados concentraram-se nas cidades de Poço Redondo $(0,0,541)$, Nossa Senhora Aparecida $(0,520)$ e São Miguel do Aleixo (0,515). Em Alagoas, Satuba (0,290), Maceió $(0,294)$ e Rio Largo (0,321) tiveram os menores índices de desigualdade medidos pelo IGE, enquanto os municípios de Traipu (0,600), Belo Monte $(0,597)$ e Santana do Mandaú $(0,561)$ apresentaram os maiores índices de desigualdade educacional, como mostra a Figura 6. 


\section{Figura 6 - Índice de Gini Educacional (IGE), Alagoas e Sergipe, 2010}

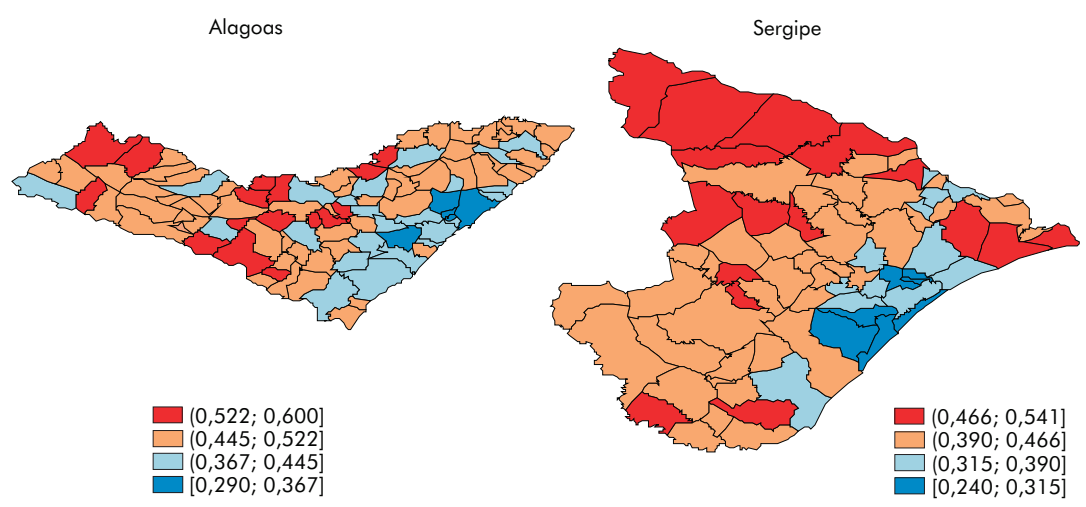

Fonte: Elaboração própria.

A Figura 7 mostra os resultados do estado da Paraíba, sendo que as cidades com menor IGE são: João Pessoa (0,257), Campina Grande $(0,292)$ e Cabedelo $(0,305)$. Aquelas com maior desigualdade são: Curral de Cima (0,543), Casserengue $(0,544)$ e Damião (0,548). Para Pernambuco (também na Figura 7), os municípios com menor desigualdade são: Paulista (0,219), Fernando de Noronha $(0,221)$ e Olinda $(0,243)$. Por outro lado, aqueles com maiores IGEs foram Águas Belas $(0,529)$, Manari $(0,530)$ e Tupanalinga $(0,530)$.

Figura 7 - Índice de Gini Educacional (IGE), Paraíba e Pernambuco, 2010
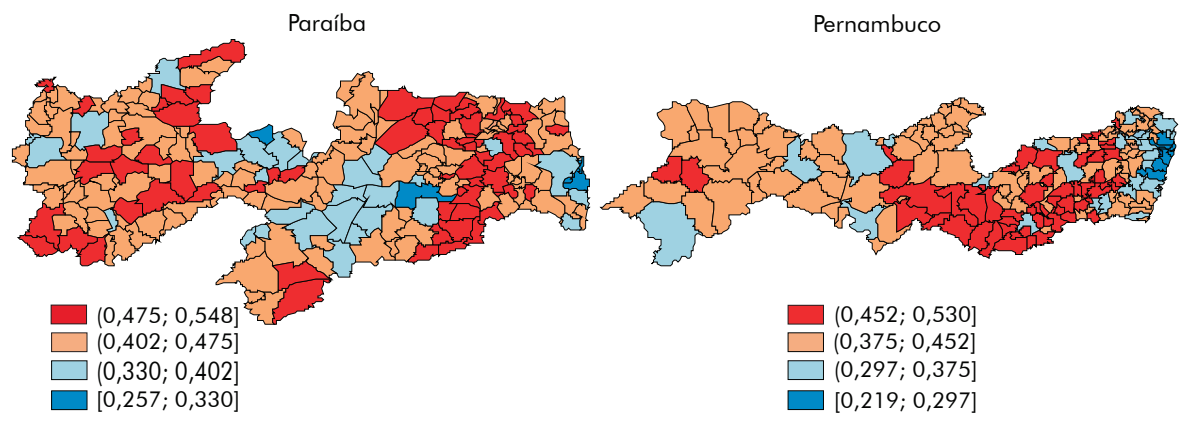

Fonte: Elaboração própria.

Por fim, dos municípios localizados no estado de Bahia (Figura 8), aqueles com menor desigualdade educacional são: Madre de Deus (0,207), Salvador (0,227) e Lauro de Freitas (0,248). Já os com maior desigualdade são Pedro Alexandre (0,586), Coronel João Sá $(0,540)$ e Itapicuru $(0,508)$. 


\section{Figura 8 - Índice de Gini Educacional (IGE), Bahia, 2010}

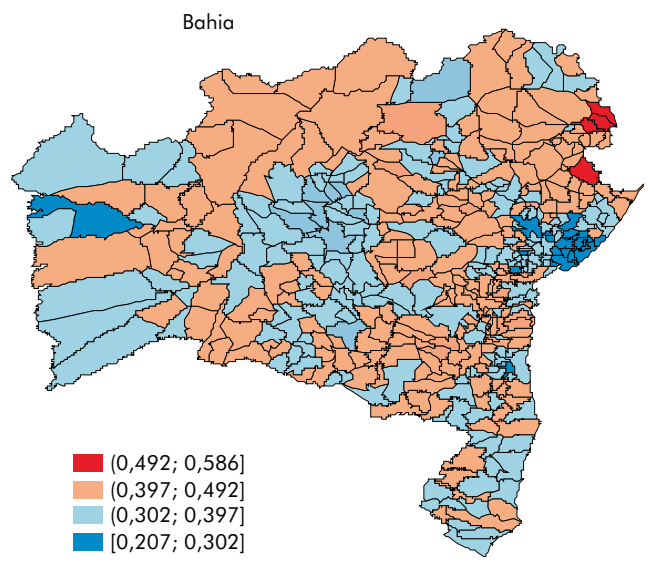

Fonte: Elaboração própria.

Vale ressaltar que, embora o Índice de Gini seja amplamente usado como medida de desigualdade, seus resultados precisam ser interpretados com cautela. Por exemplo, se dois municípios têm o mesmo IGE, mas um tem sua população predominantemente analfabeta e o outro possui pessoas com ensino superior, então, no caso do primeiro, ele estaria medindo a desigualdade da população sem nenhuma instrução, enquanto, no segundo, estaria sendo medida a desigualdade escolar nos níveis mais elevados. Dizer que o IGE é menor em uma região não quer dizer que existam ali pessoas com escolaridade mais elevada, mas sim que a distribuição educacional entre os indivíduos é mais homogênea, o que pode estar relacionado à baixa ou alta escolaridade.

\subsection{ANÁLISE DA AUTOCORRELAÇÃO ESPACIAL}

Como o objetivo é encontrar a existência de autocorrelação espacial do IGE, o teste de I-Moran foi utilizado para detectar a dependência espacial global, e o LISA para análise das aglomerações locais, onde é possível identificar a existência de clusters, dados os valores apresentados pela IGE no espaço.

A Figura 9 apresenta a dispersão de I-Moran, que foi obtida a partir da matriz de continuidade do tipo Queen ${ }^{6}$. No eixo vertical, observam-se os valores espaciais defasados da variável de interesse (Wy) e, no eixo horizontal, a variável dependente (y), ou seja, o Índice de Gini Educacional. Portanto, com a análise dos resultados apresen-

\footnotetext{
6 A matriz de Queen foi rejeitada por apresentar I-Moran menor que o da matriz Rook.
} 
tados, fica clara a existência de autocorrelação espacial positiva do IGE entre os municípios. Nos quadrantes, que representam os quatro tipos de associação linear entre os municípios e seus vizinhos, a concentração é maior nos quadrantes Baixo-Baixo e Alto-Alto. O quadrante Alto-Alto mostra a concentração de municípios com alta desigualdade, próximos a outros que também apresentam alta desigualdade educacional. Da mesma forma, o quadrante Baixo-Baixo mostra a concentração de municípios com baixa desigualdade, próximos a outros também com IGE baixo.

Portanto, o teste de I-Moran positivo sugere que existe uma similaridade entre os municípios. Em outras palavras, a autocorrelação espacial positiva revela que, em geral, os valores altos assumidos pela variável de interesse $(y)$ tendem a estar próximos de municípios com valores altos (vizinhança $(W y)$ ), assim como os valores baixos de y tendem a estar na vizinhança de valores também baixos.

Figura 9 - Índice de I-Moran para o Índice de Gini Educacional (IGE), Nordeste, 2010

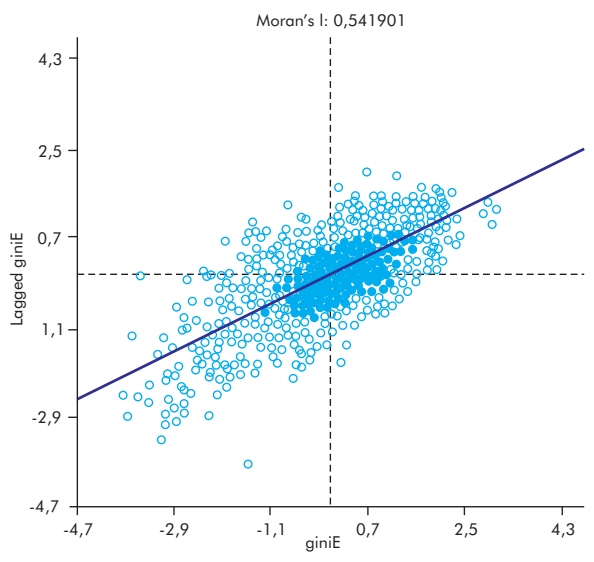

Fonte: Resultado da pesquisa, Software GeoDa.

O indicador de associação espacial global não é eficiente para identificar a formação de clusters e outliers. Nesse caso, com a utilização do teste LISA é possível visualizar a autocorrelação espacial verificada no teste de I-Moran. Como pode ser observado na Figura 10, o IGE, em 2010, apresentava certo padrão de autocorrelação espacial em algumas localidades. Identifica-se a presença de grandes cluster do IGE Alto-Alto (HighHigh) nos estados do Piauí e de Alagoas. Também é possível verificar que municípios próximos das respectivas capitais dos estados apresentam IGE Baixo-Baixo (Low-Low). As áreas em cinza representam os municípios cuja associação não foi significativa do ponto de vista estatístico (1209 no total). A associação espacial low-high (ou outliers) formada por municípios com IGE baixo próximos àqueles que apresentam índice de desigualdade alto - foi encontrada entre 30 municípios. Já o padrão high-low foi verificado entre 27 municípios, estando estes munícipios mais concentrados no estado da Bahia. 
Figura 10 - LISA para o Índice de Gini Educacional7 (IGE), Nordeste, 2010

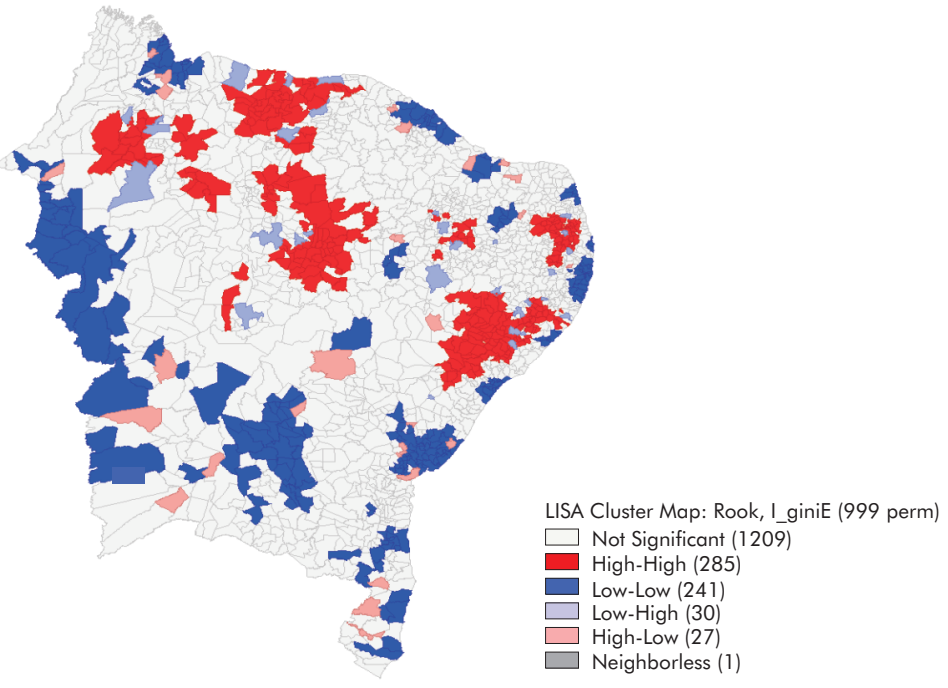

Fonte: Resultado da pesquisa, Software GeoDa.

\subsection{RESULTADOS DOS MODELOS DE REGRESSÃO ESPACIAL}

Para analisar a associação espacial entre o IGE e algumas variáveis relacionadas ao contexto familiar, educacional e econômico de um determinado município, foi utilizada a matriz de peso espacial de primeira ordem Rook. Inicialmente, foi estimada uma regressão pelo Método dos Mínimos Quadrados Ordinários (MQO), e, em seguida, o teste para saber se a autocorrelação está associada à dependência espacial ou ao termo do erro. Os resultados das regressões são apresentados na Tabela 3.

Como explicado na seção 3, o MQO não é o modelo mais eficiente para analisar os resultados dos coeficientes, visto que seus resultados não são confiáveis, uma vez que existe dependência espacial entre os municípios (confirmada pelo I-Moran). Entretanto, é necessário estimá-lo para definir qual é o melhor modelo espacial a ser analisado. Uma das estratégias para a escolha da especificação é seguir as instruções sugeridas por Florax, Folmer e Rey (2003), segundo os quais o melhor modelo é aquele que apresenta o maior nível de significância do multiplicador lagrangeano robusto. Nesse caso, pelas estatísticas do LM, existe tanto dependência espacial como autocorrelação no termo do erro, logo, o melhor modelo para interpretar os coeficientes estimados é o modelo SAC, que incorpora tanto a autorregressividade espacial da variável

\footnotetext{
7 Foram utilizadas 999 permutações.
} 
dependente quanto a autocorrelação espacial do erro. Também se confirma pela segunda estratégia de escolha, na qual o modelo estimado mais adequado é aquele que apresentar os menores critérios de informações do AIC e BIC, bem como o maior valor do LIK, como pode ser observado na Tabela 4.

Tabela 3 - Resultado do modelo de Mínimos Quadrados Ordinários (MQO) e dos Testes para Autocorrelação Espacial

\begin{tabular}{|c|c|c|c|}
\hline \multirow{2}{*}{ VARIÁVEIS } & \multicolumn{3}{|c|}{ MQO } \\
\hline & Estimativas & E.P & p-valor \\
\hline Lnrdcp & $-0,0933$ & 0,0057 & 0,000 \\
\hline chefe_es & $-0,0009$ & 0,0013 & 0,497 \\
\hline chefe_es2 & 0,0000 & 0,0001 & 0,799 \\
\hline Tx_ab_EF & 0,0019 & 0,0004 & 0,000 \\
\hline Tx_ab_EM & $-0,0001$ & 0,0002 & 0,453 \\
\hline Tx_bruta_ef & $-0,0008$ & 0,0002 & 0,001 \\
\hline Tx_bruta_em & $-0,0003$ & 0,0001 & 0,001 \\
\hline Tx_liquida_ef & 0,0032 & 0,0005 & 0,000 \\
\hline Tx_liquida_em & $-0,0012$ & 0,0002 & 0,000 \\
\hline Ies & $-0,0077$ & 0,0028 & 0,005 \\
\hline gini_renda & 0,0218 & 0,0231 & 0,346 \\
\hline ln_pib & $-0,0201$ & 0,0029 & 0,000 \\
\hline Constant & 0,9495 & 0,0509 & 0,000 \\
\hline $\mathrm{R}^{2}$-ajustado & 0,5144 & & \\
\hline \multicolumn{4}{|c|}{ Testes para Autocorrelação Espacial } \\
\hline I de Moran & 36,10 & & 0,000 \\
\hline ML (defasagem) & $1.277,70$ & & 0,000 \\
\hline ML (defasagem) robusto & 202,00 & & 0,000 \\
\hline ML (erro) & $1,197,23$ & & 0,000 \\
\hline ML (erro) robusto & 121,53 & & 0,000 \\
\hline Número de Observações & 1.793 & & \\
\hline
\end{tabular}

Nota: Nível de significância: $<5 \%$.

Fonte: Elaboração própria a partir dos dados da pesquisa.

A diferença entre os modelos expostos na Tabela 4 consiste basicamente na magnitude dos parâmetros, não havendo muita diferença nos sinais das variáveis estimadas. Os sinais também estão condizentes com o esperado para a maioria das variáveis nos modelos especificados, variando apenas os níveis de significância. Observa-se também que as variáveis que têm mais impacto sobre a desigualdade educacional são o ln da renda domiciliar per capita (-), a escolaridade dos chefes de família (-), a taxa de abandono no ensino fundamental $(+)$, a taxa de frequência escolar líquida do ensino fundamental $(+)$ e médio (-), a presença de IES (-), o gini renda (+) e o ln do PIB per capita municipal (-), todos estatisticamente significantes a um nível de confiança de $99 \%$. 
Como analisado por Langoni (1974) e Suliano e Siqueira (2012), grande parte do aumento da renda dos indivíduos está relacionada ao nível de escolaridade alcançado. Portanto, dos resultados encontrados, a renda domiciliar per capita mostrou sinal negativo em relação ao IGE. Em outras palavras, quanto maior a renda domiciliar per capita nos municípios, menor será a desigualdade em termos educacionais.

Tabela 4 - Estimativas dos Modelos Espaciais

\begin{tabular}{|c|c|c|c|}
\hline VARIÁVEIS & SAR & SEM & SAC \\
\hline \multirow{2}{*}{ Lnrdcp } & $-0,0837^{* * *}$ & $-0,0915^{* * *}$ & $-0,0843^{* * *}$ \\
\hline & $(0,00435)$ & $(0,00483)$ & $(0,00437)$ \\
\hline \multirow{2}{*}{ chefe_es } & $-0,00566^{* * *}$ & $-0,00294^{\star *}$ & $0,00577^{* * *}$ \\
\hline & $(0,00102)$ & $(0,00126)$ & $(0,00103)$ \\
\hline \multirow{2}{*}{ chefe_es2 } & $0,000351^{* * *}$ & $0,000168^{*}$ & $-0,000358^{* * *}$ \\
\hline & $(6,96 \mathrm{e}-05)$ & $(8,92 \mathrm{e}-05)$ & $(7,00 \mathrm{e}-05)$ \\
\hline \multirow{2}{*}{ Tx_ab_EF } & $0,00103^{* * *}$ & $0,00162^{* * *}$ & $0,00103^{* * *}$ \\
\hline & $(0,000273)$ & $(0,000328)$ & $(0,000274)$ \\
\hline \multirow{2}{*}{ Tx_ab_EM } & $-0,000101$ & $-4,32 \mathrm{e}-05$ & $-0,000104$ \\
\hline & $(0,000114)$ & $(0,000141)$ & $(0,000114)$ \\
\hline \multirow{2}{*}{ Tx_bruta_ef } & $-0,000223^{*}$ & $-0,000827^{\star \star \star}$ & $-0,000245^{\star}$ \\
\hline & $(0,000133)$ & $(0,000168)$ & $(0,000134)$ \\
\hline \multirow{2}{*}{ Tx_bruta_em } & $-9,93 e-05$ & $-0,000326^{\star * *}$ & $-0,000101$ \\
\hline & $(8,43 e-05)$ & $(0,000101)$ & $(8,46 \mathrm{e}-05)$ \\
\hline \multirow{2}{*}{ Tx_liquida_ef } & $0,00164^{* * *}$ & $0,00316^{* * *}$ & $0,00168^{* * *}$ \\
\hline & $(0,000346)$ & $(0,000425)$ & $(0,000347)$ \\
\hline \multirow{2}{*}{ Tx_liquida_em } & $-0,000987^{\star * *}$ & $-0,00116^{* * *}$ & $-0,000995^{\star * *}$ \\
\hline & $(0,000165)$ & $(0,000199)$ & $(0,000166)$ \\
\hline \multirow{2}{*}{ Ies } & $-0,0102^{* * *}$ & $-0,0160^{* * *}$ & $-0,0109^{* * *}$ \\
\hline & $(0,00212)$ & $(0,00279)$ & $(0,00216)$ \\
\hline \multirow{2}{*}{ gini_renda } & $0,0734^{* * *}$ & $-0,0149$ & $0,0682^{* * *}$ \\
\hline & $(0,0178)$ & $(0,0200)$ & $(0,0180)$ \\
\hline \multirow{2}{*}{ ln_ppc } & $-0,0113^{* * *}$ & $-0,0152^{* * *}$ & $-0,0114^{* * *}$ \\
\hline & $(0,00230)$ & $(0,00264)$ & $(0,00231)$ \\
\hline \multirow{2}{*}{ Constante } & $0,860^{* * *}$ & $0,897^{* * *}$ & $0,865^{* * *}$ \\
\hline & $(0,0386)$ & $(0,0471)$ & $(0,0388)$ \\
\hline \multirow{2}{*}{$\rho$} & $0,1255234^{* * *}$ & - & $0,00304^{\star *}$ \\
\hline & $(0,0030385)$ & - & $(0,00132)$ \\
\hline \multirow{2}{*}{$\lambda$} & - & $0,0151458^{* * *}$ & $0,122^{* * *}$ \\
\hline & - & $(0,0011262)$ & $(0,00343)$ \\
\hline AIC & $-7.279,012$ & $-6.601,559$ & $-7.281,982$ \\
\hline BIC & $-7.196,638$ & $-6.519,184$ & $-7.194,115$ \\
\hline LIK & $3.654,506$ & $3.315,779$ & $3.656,991$ \\
\hline
\end{tabular}

Nota: Erros padrões entre parênteses. ${ }^{* *} p<0,01,{ }^{* *} p<0,05,{ }^{*} p<0,1$.

Fonte: Elaboração própria a partir dos dados da pesquisa. 
A escolaridade do chefe de família se mostrou positivamente associada ao IGE, indicando sua contribuição para o aumento da desigualdade educacional. Esse resultado pode estar associado à influência dos pais sobre os demais membros da família, sobretudo os filhos, o que gera um efeito transbordamento no aumento da escolarização dos indivíduos (FERREIRA e VELOSO, 2003). No entanto, no curto prazo, esse efeito aumenta a desigualdade, visto que o número de famílias com os chefes com ensino superior completo é menor do que o daquelas famílias com escolaridade inferior. O sinal negativo da variável chefe_es 2 mostra que, à medida que aumenta a escolaridade dos chefes, o IGE educacional nos municípios se reduz.

Segundo Barros, Franco e Mendonça (2007), a educação e outras formas de capital humano se relacionam com a desigualdade de renda por dois canais. A primeira está relacionada ao aumento da renda pelo crescimento da escolaridade dos indivíduos, ou seja, quanto maior for a desigualdade em capital humano, maior será a desigualdade de renda. E, por outro lado, dado um grau de desigualdade em capital humano, quanto maior for a sensibilidade da remuneração a essa variável, maior será a desigualdade em remuneração. Portanto, a relação entre o IGE e o Índice de Gini renda mostrou resultados significantes e positivos, o que significa que, ao manter outras variáveis constantes e aumentar a desigualdade de renda nos municípios em um escore, a desigualdade educacional aumentará em 0,06 escores, confirmando que a educação tem forte peso sobre a renda dos indivíduos, assim como a literatura tem confirmado (SULIANO e SIQUEIRA, 2012).

Assim como destacado no estudo de Viana, Salvato e França (2011), que analisaram a desigualdade de renda e educacional entre as regiões e os estados brasileiros, o IGE e o Gini renda seguem na mesma direção, isto é, quanto maior for a desigualdade educacional de uma região, maior será a desigualdade de renda entre os indivíduos.

O PIB per capita municipal foi estatisticamente significante e negativo, o que sugere que, em municípios onde há maior produção econômica, a população residente tende a ter uma educação mais homogênea. Esses municípios, além de possuírem melhores oferta de ensino, como escolas de ensino médio e centros de ensino superior, também apresentam a vantagem de atrair mão de obra qualificada, uma vez que trabalhadores mais qualificados são atraídos pelas regiões mais desenvolvidas (TAVEIRA e ALMEIDA, 2014).

Em relação às variáveis do sistema de ensino do município, observa-se que apenas a taxa de abandono no ensino fundamental foi estatisticamente significante e positiva a $1 \%$. Ou seja, quanto maior for a proporção de alunos que abandonam a escola no ensino fundamental, maior é a desigualdade nesse município. Já quanto às taxas de frequência bruta, somente a do ensino fundamental apresentou o sinal esperado, ou seja, negativo, mas em nível de significância de 10\%. A taxa de frequência líquida que considera a adequação série/idade, que representa o percentual da população de um 
determinado grupo etário que está frequentando a série recomendada à sua idade, apresentou sinal positivo para o ensino fundamental e negativo no ensino médio. Este resultado mostra que manter as crianças na escola na idade certa, sobretudo no ensino médio, é importante para reduzir a desigualdade educacional no município.

Verifica-se ainda a importância da oferta do ensino superior nos municípios para reduzir a desigualdade no longo prazo, sendo que a proximidade dos municípios com outros polos de IES diminui a desigualdade em 0,010 escore.

\section{CONSIDERAÇÕES FINAIS}

Embora nos últimos anos o acesso à educação tenha aumentado consideravelmente entre todas as faixas de idade e tendo havido quase a universalização do ensino fundamental, a continuidade dos estudos da população em idade escolar ainda é um dos grandes desafios do sistema educacional brasileiro, o que tem prejudicado o aumento da escolaridade da população. Como mostrou o Censo Demográfico de 2010, quase $60 \%$ da população adulta dos estados nordestinos não havia completado sequer o ensino fundamental.

O presente estudo teve como objetivo contribuir com a literatura sobre desigualdade educacional calculando o IGE dos municípios da Região Nordeste, de modo a demonstrar a heterogeneidade educacional dentro dos estados e também analisar a dependência espacial entre eles. Utilizando-se o método de análise espacial e os testes de I-Moral e LISA, foi detectada a presença de clusters entre os municípios. Este achado mostra a existência de municípios com baixa ou alta desigualdade educacional próximos àqueles com características similares, o que confirma a autocorrelação espacial, no que tangencia o IGE, nos municípios nordestinos.

Quando aplicado o modelo de erro espacial, foi verificado que a ocorrência de mudanças em um município nordestino é capaz de transbordar para a sua vizinhança. Além disso, constatou-se que as variáveis renda per capita, escolaridade do chefe de família, taxa de abandono escolar no ensino fundamental, frequência escolar líquida, a presença de IES, Gini renda e o PIB per capita municipal foram estatisticamente significantes ao nível de 5\%, sendo que a escolaridade do chefe do domicílio, a taxa de abandono escolar do ensino fundamental, a frequência líquida do ensino fundamental e o Gini da renda apresentaram relação positiva com IGE.

As variáveis relacionadas ao sistema educacional mostraram ter pouco impacto na redução da desigualdade educacional, mas é importante ressaltar que o IGE foi construído pelos níveis de escolaridade da população economicamente ativa de 15 anos ou mais, sendo que a maioria dela já estava fora da escola. Nesse contexto, o investimento 
e as políticas públicas educacionais só terão reflexo na redução da desigualdade somente no futuro.

Em termos de política educacional, chamou mais atenção a necessidade de melhorar a educação básica, tendo em vista que isto pode reduzir as taxas de abandono nas escolas primárias e secundárias, o que leva a um melhor desempenho escolar em um sentido quantitativo. Essas políticas devem se voltar, principalmente, para o ensino fundamental, pois deixar a escola ainda em idade precoce dificulta o retorno a ela, o que gera mais desigualdade entre os indivíduos. E como as reformas e os investimentos educacionais levam relativamente muito tempo para afetar a oferta de mão de obra qualificada, a expansão educacional deve ser acompanhada de uma educação de qualidade, de modo a contribuir com a produtividade dos trabalhadores.

No entanto, ainda há muito a se averiguar em relação à desigualdade de educação entre os municípios, já que o IGE não incorpora os aspectos relacionados à qualidade do ensino. Assim, além dos dados quantitativos, também é importante analisar a desigualdade educacional em um quadro mais completo, com utilização de dados de desempenho cognitivo dos municípios para aprofundar a compreensão da desigualdade.

\section{REFERÊNCIAS}

ALMEIDA, E. S. Econometria espacial aplicada. Campinas: Alínea Editora, v. 1, 2012.

ALMEIDA, E. S. Curso de econometria espacial aplicada. Piracicaba: ESALQ-USP, 2004.

BAGOLIN, I. P.; PORTO, JR., S. S. A desigualdade da distribuição da educação e crescimento no Brasil: Índice de Gini e anos de escolaridade. Porto Alegre: UFRGS, 2003.

BARRO, R. J.; LEE, J. W. A new data set of educational attainment in the world, 1950-2010. Journal of Development Economics, v. 104, p. 184-198, 2010.

BARROS, R.; HENRIQUES, R.; MENDONÇA, R. Pelo fim das décadas perdidas: educação e desenvolvimento sustentado no Brasil. Texto para Discussão, IPEA, Rio de Janeiro, n. 857, 2002. Disponível em: <http://189.21.130.7/pub/td/2002/td_0857.pdf >. Acesso em: 3 fev. 2015.

BARROS, R. P.; FRANCO, S.; MENDONÇA, R. A recente queda na desigualdade de renda e o acelerado progresso educacional brasileiro da última década. Rio de Janeiro: Ipea, 2007.

BECKER, G. S. Investiment in human capital: a theoretical analysis. The Journal of Political Economy, v. 70, p. 9-49, out. 1962.

BRETON, T. R. The quality vs. the quantity of schooling: What drives economic growth? Economicsof Education Review, v. 30, n. 4. p. 765-773, 2011.

BRITO, D. J. M.; SILVA, M. V. A; SILVA, M. V. B. Uma análise espacial do crescimento da renda do trabalho dos municípios nordestinos. Economia e Desenvolvimento, Recife v. 12, n. 2, 2013. 
CASTRO, M. Educação para o Século XXI: Desafio da Qualidade e da Equidade. Brasília: INEP, 2000.

FERREIRA, S. G.; VELOSO, F. A. Mobilidade Intergeracional de Educação no Brasil. Pesquisa e Planejamento Econômico, v. 33, n. 3, p. 481-513, 2003.

FLORAX, R. J. G. M.; FOLMER, H.; REY, S. J. Specification Searches in Spatial Econometrics: the relevance of Hendry's methodology. EconWPA, p. 30, 2003.

GOLGHER, A. B. Introdução à Econometria Espacial. Jundiaí: Paco Editorial, 2015.

HANUSHEK, E. A. Economic growth in developing countries: the role of human capital. Economics of Education Review. v. 37, p. 204-212, 2013.

HANUSHEK, E. Incentives for Efficiency and Equity in the School System. Perspektiven der Wirtschaftspolitik, v. 9, p. 5-27, 2008.

HANUSHEK, E. A.; KIMKO, D. D. Schooling. Labor Force Quality and the Growth of Nations. American Economic Review, v. 90, n. 5, p. 1184-1208, 2000.

HANUSHEK, E. A; WOBMANN, L. Education and Economic Growth. International Encyclopedia of Education, v. 2, p. 245-252, 2010.

HOFFMANN, R. Distribuição de renda e crescimento econômico. Estudos Avançados, v. 15, n. 41, 2001.

LANGONI, C. G. Distribuição da renda: uma versão para a minoria. Pesquisa e Planejamento Econômico, v. 4, p.167-180, 1974.

MEDEIROS, C. N.; SALES, R. D. S.; COUTO, V. H. M. IDHM de 2010 do Ceará: análise a partir do Atlas de Desenvolvimento Humano da PNUD. Informe, v. 62, 2013.

MENEZES-FILHO, N. A. A evolução da educação no Brasil e seu impacto no mercado de trabalho. Instituto Futuro Brasil, 2001.

MENEZES-FILHO, N. A. Os Determinantes do Desempenho Escolar do Brasil. Instituto Futuro Brasil. São Paulo: Ibmec-SP e FEA-USP, 2008.

NETTO JR., J. L. S.; FIGUEIREDO, E. A. Distribuição de capital humano e desigualdade de renda: Mobilidade Intergeracional Educacional e Mobilidade de Renda no Brasil. Revista Economia e Desenvolvimento, v. 8, n. 1, 2010.

PÉREZ, G. Dimensión espacial de la pobreza en Colombia. Documentos de Trabajo sobre Economía Regional, n. 54, 2005.

SERGEI S, D.; SOARES, N. O.; FONTOURA, L. P. Tendências Recentes na Escolaridade e no Rendimento de Negros e de Brancos, 2007.

SOARES, S. S. D.; FONTOURA, N. D. O.; PINHEIRO, L. “Tendências recentes na escolaridade e no rendimento de negros e de brancos”. In: BARROS. R. P. D.; FOGUEL. M. N.; ULYSSEA. G. Desigualdade de renda no Brasil: uma análise da queda recente. Brasília: Ipea, 2007, v. II, p. 401-415.

SCHULTZ, T. W. Capital formation by education. Journal of political economy, Chicago, v. 68, n. 6, p. 571-583, dez. 1960.

SOUZA, M. M. C. O analfabetismo no Brasil sob enfoque demográfico. Cadernos de Pesquisa, n. 107, p. 169-186, jul. 1999. 
SULIANO, D. C.; SIQUEIRA, M. L. Retornos da educação no Brasil em âmbito regional considerando um ambiente de menor desigualdade. Economia Aplicada, v. 16, n. 1, p. 137-165, 2012.

SYLWESTER, K. Can education expenditures reduce income inequality? Economics of Education Review, v. 21, n. 1. p. 43-52, 2002.

TAVEIRA, J. G.; ALMEIDA, E. Os Determinantes Regionais da Atração do Migrante Qualificado. Análise Econômica, Porto Alegre, ano 32, n. 62, p. 199-224, set. 2014.

THOMAS, V.; WANG. Y.; FAN, X. Measuring Education Inequality: Gini Coefficients of Education Measuring Education Inequality. Gini Coefficients of Education, p. 1-37, 2000.

VIANA, J. S.; SALVATO, M. A.; FRANÇA, N. C. A Desigualdade Educacional é importante para explicar a Desigualdade de Renda? Uma análise para Brasil, Regiões e Unidades da Federação entre 2003 e 2009. In: Encontro Nacional de Economia/ANPEC, 39, Foz do Iguaçu, dez. 2011.

VIEIRA, C.; ALBERT, C.; BAGOLIN, I. Crescimento e desenvolvimento econômico no Brasil: uma análise comparativa entre o PIB per capita e os níveis educacionais. Análise, v. 19, n. 1. p. 28-50, 2008.

YWATA, A. X. C.; ALBUQUERQUE, P. H. M. Métodos e modelos em econometria espacial: uma revisão. Revista Brasileira de Biometria, v. 29, n. 2. p. 273-306, 2011. 